\title{
Article \\ Thermometric Characterization of Fluorescent Nanodiamonds Suitable for Biomedical Applications
}

\author{
Francisco Pedroza-Montero ${ }^{1} \mathbb{D}$, Karla Santacruz-Gómez ${ }^{2}{ }^{\mathbb{D}}$, Mónica Acosta-Elías ${ }^{3}$, Erika Silva-Campa ${ }^{3}$, \\ Diana Meza-Figueroa ${ }^{4}$ (D) Diego Soto-Puebla ${ }^{3}$ D, Beatriz Castaneda ${ }^{2}$, Efraín Urrutia-Bañuelos ${ }^{3}$, \\ Osiris Álvarez-Bajo ${ }^{3}$, Sofía Navarro-Espinoza ${ }^{5}$, Raúl Riera ${ }^{3}$ and Martín Pedroza-Montero ${ }^{3, *(D)}$
}

1 Physics PhD Program, Department of Physics Research, University of Sonora, Rosales and Encinas, Hermosillo 83000, Sonora, Mexico; a212203679@unison.mx

2 Department of Physics, University of Sonora, Rosales y Encinas, Hermosillo 83000, Sonora, Mexico; karla.santacruz@unison.mx (K.S.-G.); beatriz.castaneda@unison.mx (B.C.)

3 Department of Physics Research, University of Sonora, Rosales and Encinas, Hermosillo 83000, Sonora, Mexico; monica.acosta@unison.mx (M.A.-E.); erika.silva@unison.mx (E.S.-C.); diego.soto@unison.mx (D.S.-P.); efrain.urrutia@unison.mx (E.U.-B.); osiris.alvarez@unison.mx (O.Á.-B.); rriera@cifus.uson.mx (R.R.)

4 Department of Geology, University of Sonora, Rosales and Encinas, Hermosillo 83000, Sonora, Mexico; diana.meza@unison.mx

5 Nanotechnology PhD Program, Department of Physics, University of Sonora, Rosales y Encinas, Hermosillo 83000, Sonora, Mexico; sofia.navarro@unison.mx

Citation: Pedroza-Montero, F. Santacruz-Gómez, K.; Acosta-Elías, M.; Silva-Campa, E.; Meza-Figueroa, D.; Soto-Puebla, D.; Castaneda, B.; Urrutia-Bañuelos, E.; Álvarez-Bajo, O.; Navarro-Espinoza, S.; et al.

Thermometric Characterization of Fluorescent Nanodiamonds Suitable for Biomedical Applications. Appl. Sci. 2021, 11, 4065. https://doi.org/ 10.3390/app11094065

Academic Editor: Nadia Lotti

Received: 9 April 2021

Accepted: 27 April 2021

Published: 29 April 2021

Publisher's Note: MDPI stays neutral with regard to jurisdictional claims in published maps and institutional affiliations.

Copyright: (c) 2021 by the authors. Licensee MDPI, Basel, Switzerland. This article is an open access article distributed under the terms and conditions of the Creative Commons Attribution (CC BY) license (https:// creativecommons.org/licenses/by/ $4.0 /)$.
* Correspondence: martin.pedroza@unison.mx

Abstract: Nanodiamonds have been studied for several biomedical applications due to their inherent biocompatibility and low cytotoxicity. Recent investigations have shown perspectives in using fluorescent nanodiamonds as nanothermometers because of their optical properties' dependence on temperature. Easy and accurate localized temperature sensing is essential in a wide variety of scientific fields. Our work demonstrated how the fluorescence spectrum of high-pressure hightemperature fluorescent nanodiamonds of three different sizes: $35 \mathrm{~nm}, 70 \mathrm{~nm}$ and $100 \mathrm{~nm}$, changes with temperature within an important biological temperature range $\left(25^{\circ} \mathrm{C}\right.$ to $\left.60{ }^{\circ} \mathrm{C}\right)$. Taking advantage of this phenomenon, we obtained nanothermic scales (NS) from the zero phonon lines (ZPL) of the $\mathrm{NV}^{0}$ and $\mathrm{NV}^{-}$colour centres. In particular, the $100 \mathrm{~nm}$-sized features the more intense fluorescence spectra whose linear dependence with temperature achieved $0.98 \mathrm{R}^{2}$ data representation values for both $\mathrm{NV}^{0}$ and $\mathrm{NV}^{-}$. This model predicts temperature for all used nanodiamonds with sensitivities ranging from $5.73 \%{ }^{\circ} \mathrm{C}^{-1}$ to $6.994 \%{ }^{\circ} \mathrm{C}^{-1}\left(\mathrm{NV}^{0}\right)$ and from $4.14 \%{ }^{\circ} \mathrm{C}^{-1}$ to $6.475 \%{ }^{\circ} \mathrm{C}^{-1}$ $\left(\mathrm{NV}^{-}\right)$. Furthermore, the non-cytotoxic interaction with HeLa cells tested in our study enables the potential use of fluorescence nanodiamonds to measure temperatures in similar nano and microcellular aqueous environments with a simple spectroscopic setup.

Keywords: nanodiamond; nanothermometer; NV centres; fluorescence; bioimaging; HeLa

\section{Introduction}

A large number of nanoparticles are currently being considered for biomedical applications, such as imaging, diagnostics and drug delivery. However, many of these nanoparticles possess intrinsic limitations for their use in biological systems, such as control of surface properties, increased dispersion in physiological solutions, biocompatibility issues and effective targeting to intracellular locations [1]. Recently, carbon nanostructures attracted the scientific community's attention due to their potential applications in biomedicine and nanoscale device engineering [2-4].

Nanodiamonds receive special attention within the range of nanocarbon materials due to their outstanding physical and chemical features [5,6]. This versatile material exhibits low cytotoxicity at the cellular level $[7,8]$ and is considered the most biocompatible of all carbon-containing derivatives $[9,10]$. Moreover, given their high surface-to-volume 
ratio [11] and charged surface [12], nanodiamonds exhibit remarkable loading/binding capacities for a wide variety of therapeutic compounds [13-17]. With highly ordered aspect ratios close to unity, nanodiamonds have shown to be biologically stable [18], enabling them to prevent stress-inflammatory and apoptotic cellular reactions [19]. Some studies have supported nanodiamonds inherently susceptible biological performance in water suspension once incubated with cells $[11,20]$.

Diamonds may contain luminescent defects or colour centres due to different impurities or defects embedded within the crystal lattice [21,22]. Amongst these diamond colour centres, the nitrogen-vacancy (NV) colour centres are the most notable as they possess a stable fluorescence spectrum spanning from the visible and near-infrared regions of the electromagnetic spectrum [22], which also broadens and quenches as the nanodiamond particle size decreases [23,24]. Characteristic emission lines are at $575 \mathrm{~nm}\left(\mathrm{NV}^{0}\right)$ and $637 \mathrm{~nm}$ $\left(\mathrm{NV}^{-}\right)$corresponding to the neutral or negatively charged centre, respectively. These colour centres are known to allocate $5\left(\mathrm{NV}^{0}\right)$ or $6\left(\mathrm{NV}^{-}\right)$electrons and give rise to two possible electronic structures [25-27]. Each charge state population can be tuned to match a maximum of luminescent intensity given an excitation's wavelength and power [28]. Additionally, an excitation wavelength within $450-575 \mathrm{~nm}$ origins that the $\mathrm{NV}$ centres continuously switch between the two charge states [29]. Further studies show that under the typical $532 \mathrm{~nm}$ excitation wavelength, the probabilities of finding the $\mathrm{NV}$ centre in the $\mathrm{NV}^{-}$and $\mathrm{NV}^{0}$ configurations are $70 \%$ and $30 \%$, respectively $[28,30]$. These optical properties make fluorescent nanodiamonds a suitable probe for bioimaging and thermic sensing applications in cellular environments [31,32]. Moreover, the $\mathrm{NV}^{-}$centre is highly photostable, with no photobleaching signs, even under high power excitation at the single-molecule level $[7,8]$.

Many cellular events are temperature dependent [33-35] and several studies have demonstrated how cancer cells exhibit a higher temperature than healthy cells due to increased metabolism $[35,36]$. At this point, accurate data on the local temperature in biological systems is necessary to understand their dynamical behaviour and general state [37]. In these systems, it is desirable to have a non-invasive method to perform local temperature measurements at micron and sub-micron scales. A solution to this problem is fluorescence thermometry, which makes use of fluorescent materials such as quantum dots, rare-earth-doped crystals [38-40], organic compounds [41,42] and nanodiamonds [43-45] to determine temperature without contact. However, doubts arise about the biocompatibility and toxicity of rare-earth-doped nanostructures [46]; for this reason, nanodiamonds are preferred due to their inherent biocompatibility [47]. Another nanodiamond advantage is NV centres are immobile at room temperature, conferring excellent stability and sensitivity [43]. Then, the thermometry based on nanodiamond fluorescence becomes an excellent alternative to assess the intracellular structures. Nevertheless, most works consider the changes in the electron spin resonances of $\mathrm{NV}^{-}$centres when a magnetic field is applied $[44,48,49]$. The obtained optically detected magnetic resonances (ODMR) of $\mathrm{NV}^{-}$centres under different temperatures have an excellent low-temperature uncertainty. Still, the implementation of those techniques demands high requirements of sophisticated experimental infrastructure [50-52]. In contrast, thermometry scales build from NV centres luminescence can be constructed with a simple experimental setup getting sensitivities around $\pm 1.3^{\circ} \mathrm{C}$ for both $\mathrm{NV}$ centres. Examples are nano-thermometry using the DebyeWeller factor (DWF), that is the ratio of the area under the ZPL and the total emission band of the $\mathrm{NV}^{-}[44,53]$, the detection of small changes in the width, the area and the peak wavelength of the ZPL [54], recording of spectral shifts of ZPL [45] or the measurement of energy level shifts of NV centres by Raman and photoluminescence (PL) spectra [50].

In this work, we performed a thermometric characterization in a biological temperature range $\left(25-60^{\circ} \mathrm{C}\right)$ of commercial high-pressure high-temperature fluorescent nanodiamonds (HPHT FNDs) with three sizes: $35 \mathrm{~nm}, 70 \mathrm{~nm}$ and $100 \mathrm{~nm}$. Our results showed that it is possible to establish nanothermic scales based on HPHT FNDs with affordable fluorescence microscope equipment. Additionally, the temperature measurement with $\mathrm{NV}^{0}$ may apport an additional calibration tool. As an early biomedical application, the thermal 
bioimage of HeLa cells at RT was obtained, opening a new perspective of using FNDs as nanothermometers in living cellular environments for thermal imaging and diagnosis aid.

\section{Materials and Methods}

\subsection{High-Pressure High-Temperature Nanodiamonds}

HPHT FNDs in aqueous solution were acquired from Sigma Aldrich with average particle sizes of $35 \mathrm{~nm}, 70 \mathrm{~nm}$ and $100 \mathrm{~nm}$ each (Table 1). HPHT FNDs of $100 \mathrm{~nm}$ of particle size were concentrated to $0.1 \%, 0.5 \%$ and $0.01 \% w / v$ with purified water (Milli-Q model C85358, Millipore Sigma) for the cytotoxicity assay and HeLa cells culture study.

Table 1. Sigma Aldrich's nanodiamonds specifications.

\begin{tabular}{cccc}
\hline Part Number & Concentration & NV Centres/Particle & Size \\
\hline $900172-5 \mathrm{~mL}$ & $1 \mathrm{mg} / \mathrm{mL}$ & $\leq 4$ & $35 \mathrm{~nm}$ \\
$798169-5 \mathrm{~mL}$ & $1 \mathrm{mg} / \mathrm{mL}$ & $>300$ & $70 \mathrm{~nm}$ \\
$900174-5 \mathrm{~mL}$ & $1 \mathrm{mg} / \mathrm{mL}$ & $>900$ & $100 \mathrm{~nm}$ \\
\hline
\end{tabular}

\subsection{Fluorescent Thermometry}

The fluorescence spectra of $35 \mathrm{~nm}$ and $70 \mathrm{~nm}$-sized nanodiamonds were recorded at different temperatures using a laser scanning confocal microscope Olympus BX41 (Japan) equipped an InGaAs detector using a 10x long working distance microscope objective with a NA 0.25 and an OBIS $532 \mathrm{~nm}$ laser with $20 \mathrm{~mW}$ of continuous power as the optical excitation. The laser was directed through a series of mirrors into the microscope system. Then, the laser was focused on the sample, the detector collected the signal, and then processed with Horiba Scientifics LabSpec software. Once these colour centres were welllocalised and the optimal microscope parameters established for a maximised output signal, fluorescence spectra were recorded at different temperatures within the physiological range of $25^{\circ} \mathrm{C}$ to $60^{\circ} \mathrm{C}$ with the help of a heating plate in steps of $1^{\circ} \mathrm{C}$ and $20 \mathrm{~min}$ of thermal equilibrium time. Fluorescence spectra were recorded using a detection range from $550 \mathrm{~nm}$ to $850 \mathrm{~nm}$ in steps of $1 \mathrm{~nm}$ with a $2 \mathrm{~nm}$ wide slit and $0.1 \mathrm{~s}$ of integration time.

The fluorescence spectra of $100 \mathrm{~nm}$-sized nanodiamonds were recorded at different temperatures using a Horiba Scientifics Fluorolog ${ }^{\circledR}-3$ FL3-22 (Japan) equipped with a photomultiplier tube Hamamatsu R928P and an OBIS $532 \mathrm{~nm}$ laser with $20 \mathrm{~mW}$ of continuous power as optical excitation. The temperature control was achieved with the F-3030 temperature bath and the FL-1027 Single-Position Thermostatted Cell Holder accessories from Horiba Scientifics. The software FluorEssense (Horiba Scientifics, Japan) was set for an emission scan from $25{ }^{\circ} \mathrm{C}$ to $60{ }^{\circ} \mathrm{C}$ in steps of $1{ }^{\circ} \mathrm{C}$ with a tolerance of $0.1^{\circ} \mathrm{C}$ and 20 min of thermal equilibrium time. The fluorescence spectra were recorded using a detection range from $550 \mathrm{~nm}$ to $850 \mathrm{~nm}$ in steps of $1 \mathrm{~nm}$ with a $2 \mathrm{~nm}$ wide slit and $0.1 \mathrm{~s}$ of integration time.

The software Origin (OriginLab, Northampton, MA, USA) was used to obtain peak information of the NV colour centres' zero phonon lines characteristics $\left(\mathrm{NV}^{0}, 575 \mathrm{~nm}\right.$ and $\mathrm{NV}^{-}, 637 \mathrm{~nm}$ ) in the form of intensity, full width at half maximum and position through a Gaussian fit. First, all the spectra were normalized from 0 to 1 . Then, they had their baseline adjusted to include the phonon sidebands below ZPL, similarly to the background subtraction performed by Plathotnik et al. [44]. Finally, they had their NV centre peaks fit with a Gaussian curve. A linear fit was calculated for the thermal evolution of the NV centres' fluorescence, yielding very accurate results regarding their $\mathrm{R}^{2}$ quality of fit value. Relative sensitivities were calculated according to the following equation:

$$
\mathrm{S}_{\mathrm{Q}}=(1 / \mathrm{Q})(\mathrm{dQ} / \mathrm{dT})
$$

where $\mathrm{S}_{\mathrm{Q}}$ represents the sensibility, $\mathrm{Q}$ is the $\mathrm{NV}$ centre's fluorescence and $\mathrm{T}$ is the temperature. 


\subsection{HeLa Images and Cytotoxicity Assays}

HeLa cells were seeded on a sterile 96 well plate and cultured in DMEM (Dulbecco's modified eagle medium), supplemented with FBS $(10 \%)$, sodium pyruvate $(1 \mathrm{mM})$, penicillin $(10 \mu \mathrm{g} / \mathrm{mL})$, streptomycin $(0.1 \mathrm{mg} / \mathrm{mL})$ and incubated at $37^{\circ} \mathrm{C}, \mathrm{CO}_{2}(5 \%)$ and $80 \%$ humidity; until reaching $80 \%$ of a monolayer.

For nanodiamonds-cells interaction, the cells were washed with phosphate-buffered saline (PBS) solution to remove non-adherents, dead and rest of metabolized medium. The $100 \mathrm{~nm}$ nanodiamonds solution concentrated to $0.01 \% w / v$ was diluted in sterile DMEM at $0.01 \% w / v$ and $200 \mu \mathrm{L}$ of the solution was added to each well, incubated for $1 \mathrm{~h}$ under the same conditions described previously. The cells were stirred in the dark, then the solution was removed, and they were subjected to 3 washing steps with PBS before observation at the microscope. The images of the interaction between nanodiamond and HeLa cells were obtained with a confocal microscope Nikon Eclipse Ti (Japan). The $532 \mathrm{~nm}$ laser beam of 5-6 $\mathrm{mW}$ was focused onto the samples by a 20x objective (air, NA 0.95) and fluorescence images $(1024 \times 1024$ pixels $)$ were processed with the imaging software NIS-Elements (Nikon, Japan).

The viability of HeLa cells exposed to nanodiamonds was measured using the wellknown 3-(4,5-dimethylthiazol-2-yl)-2,5-diphenyltetrazolium bromide (MTT) assay. For this assay, serial dilutions of nanodiamonds were prepared in a sterile saline solution of DMEM $\left(10^{-2}, 10^{-3}, 10^{-4}, 10^{-5}, 10^{-6}, 10^{-7}\right.$ and $0 \%$ as a viability control). The culture medium was removed and replaced with each dispersion of nanodiamonds solutions (four replicates for each concentration per assay). The protocol was previously reported by Fernández-Quiroz in 2019 [55]. MTT was diluted in PBS $(5 \mathrm{mg} / \mathrm{mL})$ and filtered through a $0.22 \mu \mathrm{m}$ sterile filter. After $24 \mathrm{~h}$ of incubation, the stimulus was removed. MTT diluted in DMEM $(100 \mu \mathrm{L}$, $12 \mathrm{mM}$ ) was added to the wells and incubated at $37^{\circ} \mathrm{C}\left(5 \% \mathrm{CO}_{2}\right)$ for $2 \mathrm{~h}$. MTT reactive was carefully removed, and a $100 \mu \mathrm{L}$ of Dimethyl sulfoxide (DMSO) was added to solubilize the formazan crystals formed. Then, the absorbance was measured at $570 \mathrm{~nm}$ in a UV spectrophotometer (Thermo Scientific Multiskan GO), and the results were compiled using SkanIt software (Thermo Fisher Scientific, Waltham, MA, USA). Unstimulated-negative control cells were incubated with the respective complete medium. Positive control cells were treated with 10\% DMSO to cause cell death. Cell viability is expressed as a percentage of the negative control, given by Equation (2).

$$
\text { Cell Viability }(\%)=\left(\mathrm{A}_{\text {Sample }} / \mathrm{A}_{\text {Control }}\right)(100 \%)
$$

where $A_{\text {Sample }}$ represents the measurement from wells treated with nanodiamonds solutions, and $\mathrm{A}_{\text {Control }}$ represents the value obtained from the wells treated with complete medium.

\section{Results and Discussion}

\subsection{NV Centre Electronic Structure}

In general, the electronic structure of the NV centre has six electrons. Two coming from the nitrogen atom, and another three are dangling bonds from the three carbon atoms surrounding the vacancy. The sixth electron is captured from the lattice, resulting in $\mathrm{NV}^{-}$ charge state [56]. During the FNDs crystal growing others NV charge states may occur, such as $\mathrm{NV}^{0}$ and $\mathrm{NV}^{+}$. Among the created centres, $\mathrm{NV}^{0}$ and $\mathrm{NV}^{-}$are optically active but only $\mathrm{NV}^{-}$is both magnetically and optically active. The electron density of those centres is distributed in a plane vertical to the central NV axis, with the highest density on the three carbon atoms and the vacant site $[57,58]$. In this scheme, the electronic structure of $\mathrm{NV}^{0}$ has a ${ }^{2} \mathrm{E}$ ground state, ${ }^{2} \mathrm{~A}_{2}$ optical excited level, and an intermediate metastable ${ }^{4} \mathrm{~A}_{2}$ level. The ${ }^{2} \mathrm{~A}_{2}$ has no orbital degeneracy and exhibits no zero-field fine structure, but the ground state ${ }^{2} \mathrm{E}$ has orbital degeneracy causing a spin-orbit fine structure [59]. For $\mathrm{NV}^{-}$centre, the ground base $\left({ }^{3} \mathrm{~A}_{2}\right)$ is a spin-triplet that at zero field state split in three sub-spin levels: a doublet $\left(\mathrm{m}_{\mathrm{s}}= \pm 1\right)$ and a singlet $\left(\mathrm{m}_{\mathrm{s}}=0\right)$. Moreover, the $\mathrm{NV}^{-}$centre presents an additional 
${ }^{1} \mathrm{~A}_{1}$ metastable state [60]. In contrast, the excited electronic state ${ }^{3} \mathrm{E}$ exhibits a complex fine structure composed mainly by spin-spin and spin-orbit interactions [61]. Figure 1a. Thermal energy enhances all the luminescent relaxation processes but also actives surface or defects states. These nonradiative relaxation channels are activated as temperature rises. The thermal relaxations may compete directly with the radiative response from ZPL in FNDs, diminishing their fluorescence signal [62].

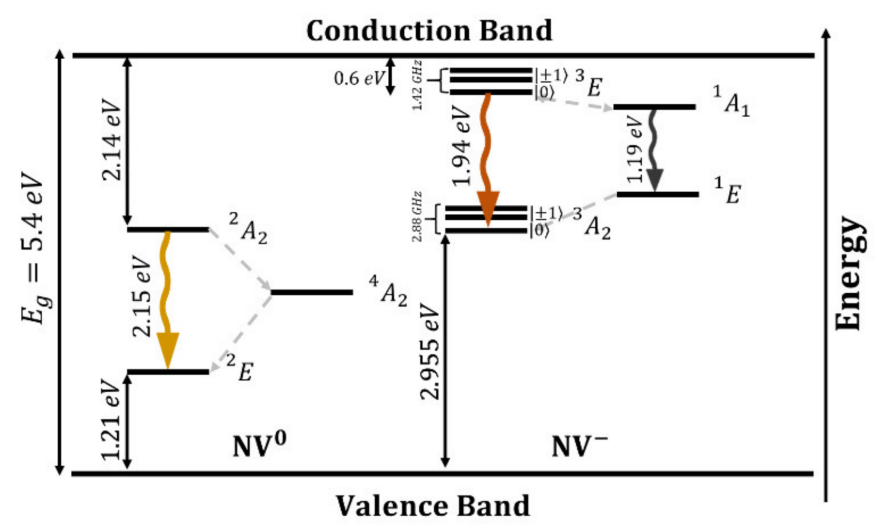

(a)

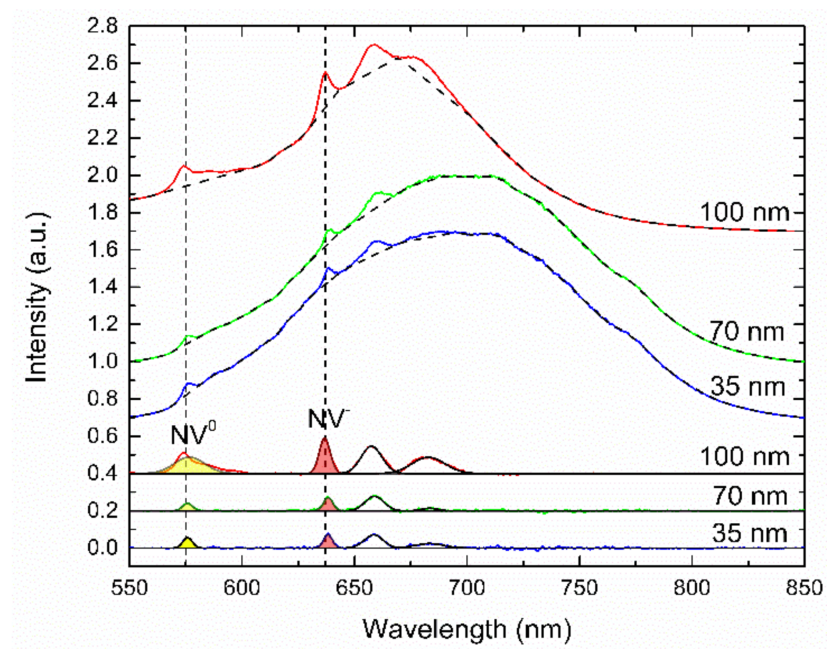

(b)

Figure 1. (a) Energy level diagram of the $\mathrm{NV}^{0}$ and $\mathrm{NV}^{-}$centres in the diamond crystal lattice. The solid arrows denote the energy separation from the energy level to the valence or conduction band, and $\mathrm{E}_{\mathrm{g}}$ is the diamond's bandgap. The dashed arrows characterize the intersystem crossing between two energy levels. The wavy coloured arrows are the observed radiative transitions. (b) Fluorescence spectra of HPHT nanodiamonds of different sizes recorded at $25^{\circ} \mathrm{C}$. The top-coloured lines are normalized fluorescence spectra, the top dashed black lines are the baselines, the bottom-coloured lines are the filtered spectra, the bottom solid black lines are the Gaussian fits, and the bottom-coloured areas correspond to fluorescence peaks of the NV centres.

\subsection{Nanothermic Scale of High-Pressure High-Temperature Nanodiamonds}

The fluorescence spectrum of $35 \mathrm{~nm}, 70 \mathrm{~nm}$ and $100 \mathrm{~nm}$-sized nanodiamonds are shown in Figure 1b. The two fluorescence peaks detected at $575 \mathrm{~nm}$ and $637 \mathrm{~nm}$ correspond to the $\mathrm{NV}^{0}$ and $\mathrm{NV}^{-}$colour centres defects' fluorescence, respectively. An energy level diagram for both charge states is shown in Figure 1a, illustrating which energy levels are found in either charge state configuration symmetry. The $\mathrm{NV}^{0}$ zero-phonon line transition ${ }^{2} \mathrm{~A}_{2}{ }^{2} \mathrm{E}$ has an energy of $2.15 \mathrm{eV}$ corresponding to $575 \mathrm{~nm}$. The $\mathrm{NV}^{-}$zero-phonon line transition ${ }^{3} \mathrm{E}^{3} \mathrm{~A}_{2}$ has an energy of $1.94 \mathrm{eV}$ corresponding to $637 \mathrm{~nm}$. The two peaks detected at $659 \mathrm{~nm}$ and $680 \mathrm{~nm}$ are $\mathrm{NV}^{-}$phonon sidebands ascribed to an electron-phonon coupling $[63,64]$. Optical excitation and emission are separated into zero-phonon lines and phonon sidebands. Vibrational properties determine the shape and extent of the phonon sidebands. In a radiative transition, the initial state is a vibrational ground state of an excited energy level, while the final state can be any vibrational state of the electronic ground state; hence, the phonon sideband transitions are usually Stokes-shifted [59,64,65]. The radiative transition ${ }^{1} \mathrm{~A}_{1}-{ }^{1} \mathrm{E}$ of energy $1.19 \mathrm{eV}$ corresponds to an infrared photon of a wavelength of $1042 \mathrm{~nm}$ and lies within the $\mathrm{NV}^{-}$electronic structure.

Our results demonstrated how the NV centres' fluorescence from nanodiamonds is sensitive to temperature changes and can be accurately described by a linear model within the $25^{\circ} \mathrm{C}$ to $60^{\circ} \mathrm{C}$ range. Figure 2 shows how both charge states' fluorescence transforms concerning to temperature changes and their nanothermic scales adjusted employing a linear fit. 


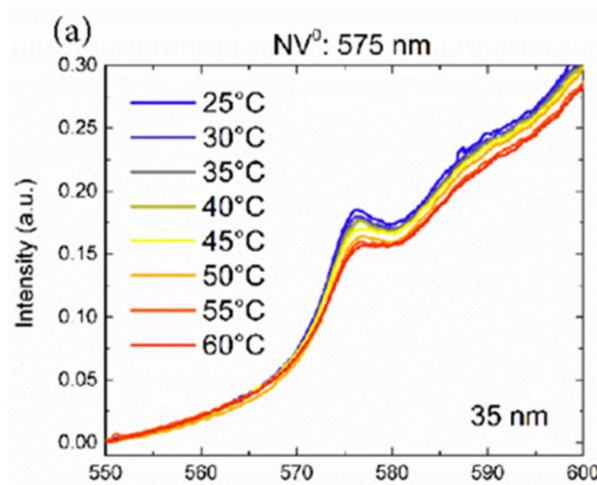

(d)

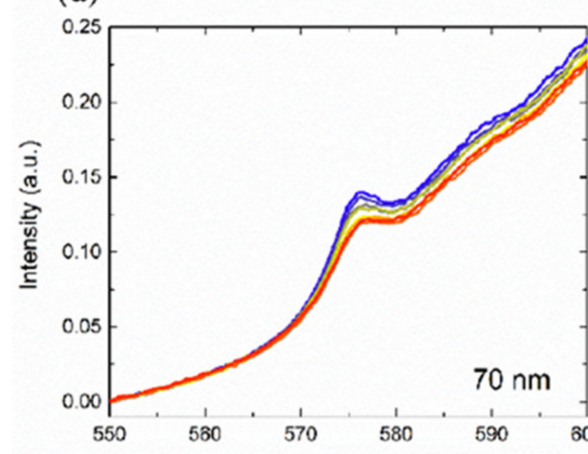

(g)

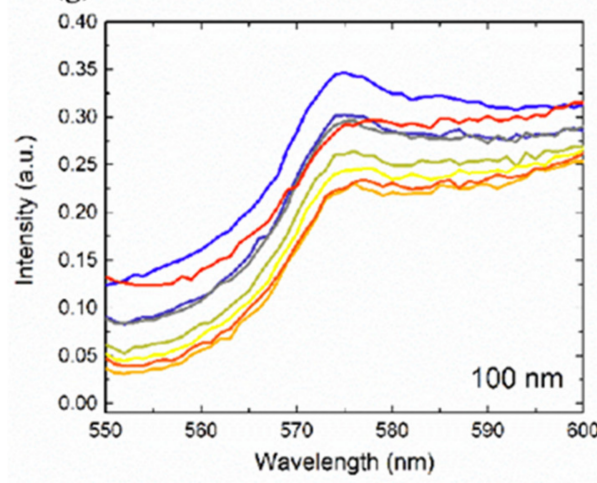

(b)

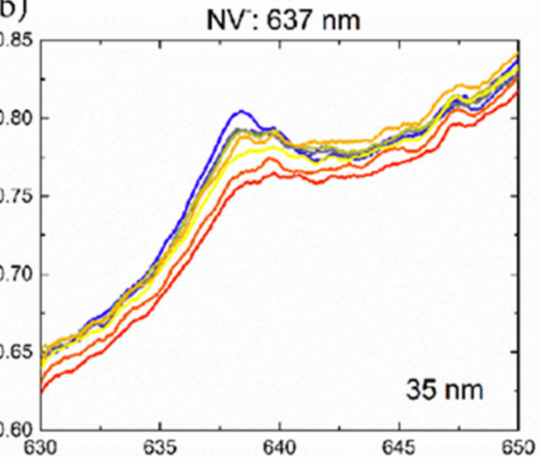

(e)

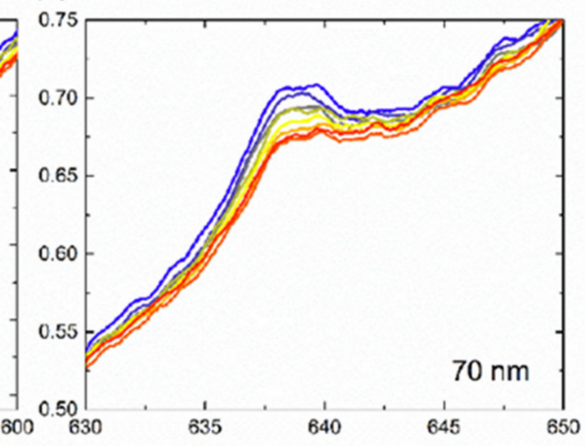

(h)

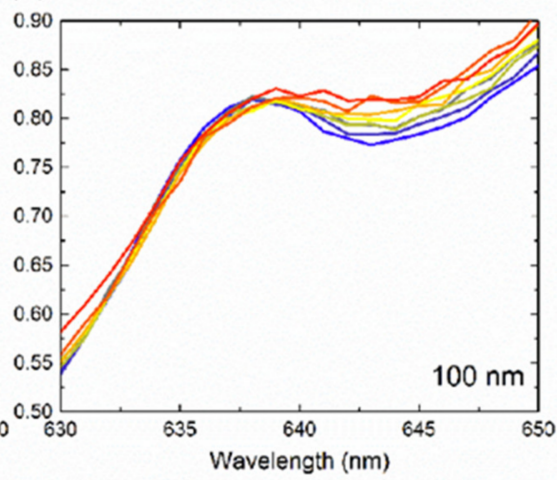

(c)

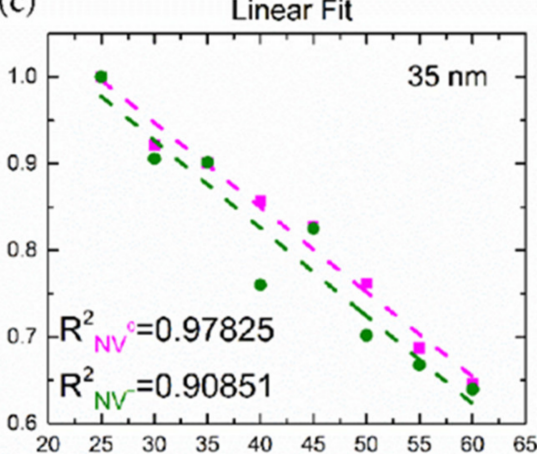

(f)

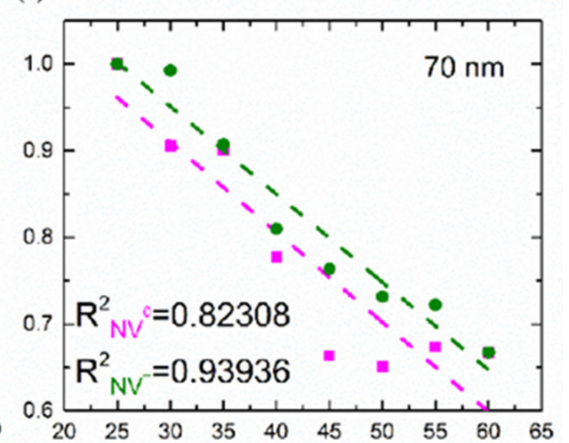

(i)

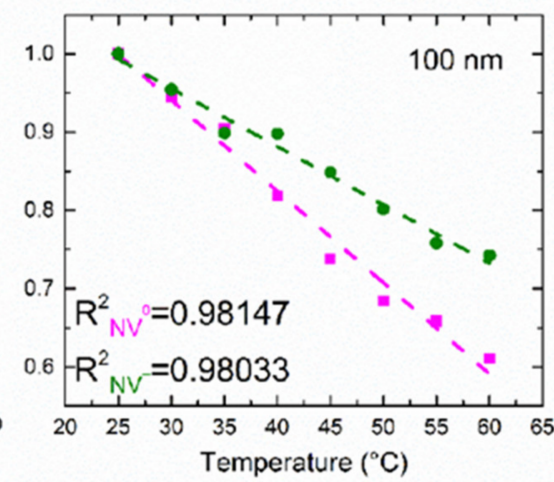

Figure 2. Fluorescence spectra of $\mathrm{NV}^{0}$ and $\mathrm{NV}^{-}$centres in HPHT nanodiamonds of $35 \mathrm{~nm}(\mathbf{a}, \mathbf{b}), 70 \mathrm{~nm}(\mathbf{d}, \mathbf{e})$ and $100 \mathrm{~nm}$ (g,h) for temperatures from $25^{\circ} \mathrm{C}$ to $60^{\circ} \mathrm{C}$. The dependence of the maximum fluorescence intensity on temperature $(\mathbf{c}, \mathbf{f}, \mathbf{i})$ is obtained through normalization and using a Gaussian model. A linear fit gives $\mathrm{R}^{2}$ values are $0.97825,0.82308$ and 0.98147 for the $\mathrm{NV}^{0}$ centre and $0.90851,0.93936$ and 0.98033 for the $\mathrm{NV}^{-}$centre, for nanodiamonds of $35 \mathrm{~nm}, 70 \mathrm{~nm}$ and $100 \mathrm{~nm}$, respectively.

The $35 \mathrm{~nm}$ nanodiamonds yielded a very accurate linear data representation and sensitivities of $97 \%, 5.37 \%{ }^{\circ} \mathrm{C}^{-1}\left(\mathrm{NV}^{0}\right)$ and $90 \%, 5.618 \% \mathrm{C}^{-1}\left(\mathrm{NV}^{-}\right)$, demonstrating outstanding thermometric performance. The $70 \mathrm{~nm}$ nanodiamonds yielded linear data representations of $82 \%, 6.365 \%{ }^{\circ} \mathrm{C}^{-1}\left(\mathrm{NV}^{0}\right)$ and $93 \%, 6.475 \%{ }^{\circ} \mathrm{C}^{-1}\left(\mathrm{NV}^{-}\right)$, performing slightly worse than the $35 \mathrm{~nm}$-sized ones. The $100 \mathrm{~nm}$ nanodiamonds performed best among all the samples. They exhibited superior linear data representations of $98 \%, 6.994 \%{ }^{\circ} \mathrm{C}^{-1}\left(\mathrm{NV}^{0}\right)$ and $98 \%$, $4.14 \%{ }^{\circ} \mathrm{C}^{-1}\left(\mathrm{NV}^{-}\right)$than the other samples, mainly attributed to their high nitrogen-vacancy centre concentration [66-68] and their enhanced fluorescence signal of the $\mathrm{NV}^{-}$dominant charge state [23]. Remarkably, the reported sensitivities represent uncertainties around \pm $1.3^{\circ} \mathrm{C}$ for both $\mathrm{NV}$ centres marginally bigger than those reported in ODMR experiments $\left(\approx 0.5-1^{\circ} \mathrm{C}\right)[69,70]$.

We observed how the $70 \mathrm{~nm}$-sized nanodiamonds' $\mathrm{NV}^{0}$ intensity exhibited an anomalous feature in the analysis, where a linear curve could only represent $82 \%$ of the data, whereas the $35 \mathrm{~nm}(93 \%)$ and $100 \mathrm{~nm}$ (98\%) sized ones reached higher $\mathrm{R}^{2}$ values. This 
fact may be attributed to $\mathrm{sp}^{2}$ carbon contamination of the surface during the growth process [71] and the proximity of NV centres to her [72]. Furthermore, the nanothermic scales for $35 \mathrm{~nm}$-sized nanodiamonds performed nearly as good as the $100 \mathrm{~nm}$-sized nanodiamonds, differing in the overall spectrum broadening due to a smaller particle size [23].

As an example of thermal bioimaging at room temperature, a fluorescence image of the HeLa cells incubated with $100 \mathrm{~nm}$ nanodiamonds is shown in Figure 3a. Moreover, their original shape remains unaltered because of a non-cytotoxic interaction. The HPHT FNDs rendered biocompatible ( $>90 \%$ ) for concentrations up to $0.1 \%$, as depicted in Figure 3b. We observe that most nanodiamonds are accumulated preferentially on the protuberance generated by the nucleus' volume (Figure 3a). This feature has been used to indirectly measure the temperature on the malignant cell's nucleus, which presents a higher gene expression rate and protein production and demands higher energy levels of ATP consumption [73]. The thermal bioimaging for measuring cell temperature of protuberances may be an efficient technique to differentiate between healthy and infected cells [74]. Improvements to thermal bioimage could be achieved with the implantation of selected ions to the surface of FNDs to slow $\mathrm{NV}^{-}$to $\mathrm{NV}^{0}$ conversion energy. Being $\mathrm{H}$, an efficient fluorescent termination as demonstrated by Kratochvílova et al. [75].

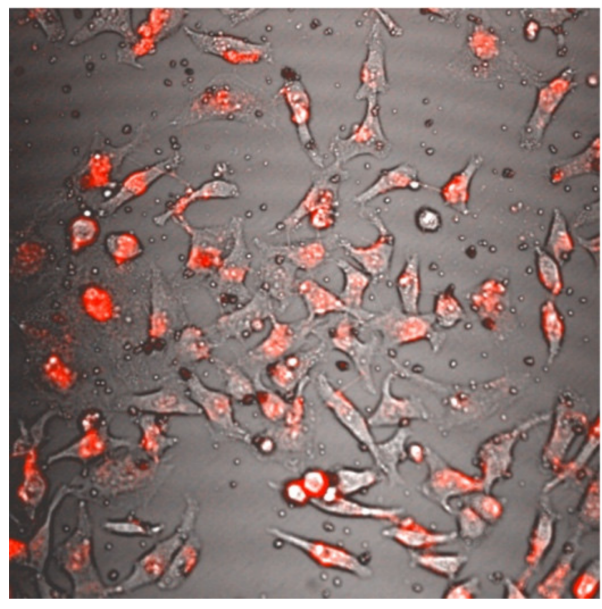

(a)

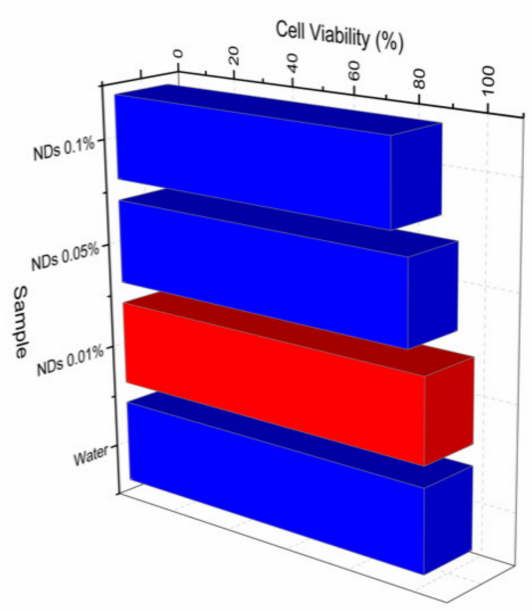

(b)

Figure 3. (a) Fluorescence of $100 \mathrm{~nm}$ HPHT FNDs in HeLa cells. The fluorescence image was recorded around the membrane after $24 \mathrm{~h}$ of incubation at $37^{\circ} \mathrm{C}$. (b) MTT Cytotoxicity assay of different concentrations of $100 \mathrm{~nm}$ HPHT FNDs in HeLa cells, the red bar corresponds to the concentration used in (a).

\section{Conclusions}

In general, the overall fluorescence intensity of the fluorescent nanodiamonds used for this work decreases as temperature rises within the range of biologically relevant temperatures $\left(25^{\circ} \mathrm{C}\right.$ to $\left.60^{\circ} \mathrm{C}\right)$. We demonstrated how this fluorescence intensity mostly follows a linear dependence with the local nanodiamond temperature. Furthermore, there is a size dependency on the processes involved in the changes in the overall fluorescence spectrum of nanodiamonds which relates the smaller nanodiamonds with a broader and less intense signal, while larger nanodiamonds with a sharper and brighter spectrum. However, the ZPL position remains unaltered in all cases, and then the fitting process can discriminate and account for them successfully.

The $\mathrm{NV}^{0}$ and $\mathrm{NV}^{-}$centres' fluorescence allowed the construction of nanothermic scales. Additionally, this study unveils the possibility of using nanodiamonds as nanothermometers to distinguish delimitation of tumoral margins and several types of pathologies through the point measurement of the membrane's temperature $(70 \mathrm{~nm}$ or $100 \mathrm{~nm}$ size nanodiamonds) or inner structures of malignant cells (with $35 \mathrm{~nm}$ or smaller nanodiamonds). 
Here, biomedical applications such as, the imaging and diagnosing instrumentation based on fluorescence became simple and could be implemented easily in biomedicals facilities inside hospitals and health clinics.

Author Contributions: Conceptualization, D.M.-F., R.R. and M.P.-M.; methodology, K.S.-G., M.A.-E. and E.S.-C.; validation, S.N.-E.; formal analysis, F.P.-M., K.S.-G., M.A.-E., E.S.-C., O.Ã.-B. and M.P.-M.; investigation, F.P.-M.; data curation, F.P.-M., K.S.-G., M.A.-E., E.S.-C. and O.Ã.-B.; writing-original draft preparation, F.P.-M.; writing—review and editing, D.M.-F., D.S.-P., B.C., E.U.-B., S.N.-E. and R.R.; supervision, M.P.-M.; project administration, M.P.-M.; funding acquisition, D.M.-F. and M.P.-M. All authors have read and agreed to the published version of the manuscript.

Funding: This research was funded by CONACYT (Mexico) under Contract PDCPN2014-01/248982 and fellowship of F. Pedroza-Montero.

Data Availability Statement: For data acquiring please send an e-mail to F.P.-M.'s institutional e-mail: a212203679@unison.mx.

Acknowledgments: Results of this paper are part of a Ph.D. thesis by F.P.-M. under the advice of M.P.-M.

Conflicts of Interest: The authors declare no conflict of interest.

\section{References}

1. Neves, A.R.; Reis, S. Nanoparticles in Life Sciences and Biomedicine; Neves, A.R., Reis, S., Eds.; Pan Stanford Publishing Pte. Ltd.: Singapore, 2018; ISBN 978-1-351-20735-5.

2. Pan, M.; Annamalai, K.; Tao, Y. Applications of Nanocarbons in Bio-Medical Devices. Recent Innov. Chem. Eng. Former. Recent Pat. Chem. Eng. 2016, 8, 67-74. [CrossRef]

3. Wang, X.; Nakamoto, T.; Dulińska-Molak, I.; Kawazoe, N.; Chen, G. Regulating the stemness of mesenchymal stem cells by tuning micropattern features. J. Mater. Chem. B 2016, 4, 37-45. [CrossRef]

4. Panwar, N.; Soehartono, A.M.; Chan, K.K.; Zeng, S.; Xu, G.; Qu, J.; Coquet, P.; Yong, K.-T.; Chen, X. Nanocarbons for Biology and Medicine: Sensing, Imaging, and Drug Delivery. Chem. Rev. 2019, 119, 9559-9656. [CrossRef] [PubMed]

5. Mitura, S. Nanodiamonds. J. Achiev. Mater. Manuf. Eng. 2007, $24,7$.

6. Nunn, N.; Torelli, M.; McGuire, G.; Shenderova, O. Nanodiamond: A high impact nanomaterial. Curr. Opin. Solid State Mater. Sci. 2017, 21, 1-9. [CrossRef]

7. Yu, S.-J.; Kang, M.-W.; Chang, H.-C.; Chen, K.-M.; Yu, Y.-C. Bright Fluorescent Nanodiamonds: No Photobleaching and Low Cytotoxicity. J. Am. Chem. Soc. 2005, 127, 17604-17605. [CrossRef]

8. Hui, Y.Y.; Cheng, C.-L.; Chang, H.-C. Nanodiamonds for optical bioimaging. J. Phys. Appl. Phys. 2010, 43, 374021. [CrossRef]

9. Vaijayanthimala, V.; Tzeng, Y.-K.; Chang, H.-C.; Li, C.-L. The biocompatibility of fluorescent nanodiamonds and their mechanism of cellular uptake. Nanotechnology 2009, 20, 425103. [CrossRef]

10. Elena, P.; Jani, M.; Cheng, C.-L. Applications of Nanomaterials; Ramesh, S.C., Shrikan, C.W., Eds.; American Scientific Publishers: Valencia, CA, USA, 2013; ISBN 978-1-58883-181-1.

11. Schrand, A.M.; Huang, H.; Carlson, C.; Schlager, J.J.; Ōsawa, E.; Hussain, S.M.; Dai, L. Are Diamond Nanoparticles Cytotoxic? J. Phys. Chem. B 2007, 111, 2-7. [CrossRef]

12. Manus, L.M.; Mastarone, D.J.; Waters, E.A.; Zhang, X.-Q.; Schultz-Sikma, E.A.; MacRenaris, K.W.; Ho, D.; Meade, T.J. Gd(III)Nanodiamond Conjugates for MRI Contrast Enhancement. Nano Lett. 2010, 10, 484-489. [CrossRef]

13. Yeap, W.S.; Chen, S.; Loh, K.P. Detonation Nanodiamond: An Organic Platform for the Suzuki Coupling of Organic Molecules. Langmuir 2009, 25, 185-191. [CrossRef] [PubMed]

14. Ali, M.S.; Metwally, A.A.; Fahmy, R.H.; Osman, R. Nanodiamonds: Minuscule gems that ferry antineoplastic drugs to resistant tumors. Int. J. Pharm. 2019, 558, 165-176. [CrossRef] [PubMed]

15. Gao, G.; Guo, Q.; Zhi, J. Nanodiamond-Based Theranostic Platform for Drug Delivery and Bioimaging. Small 2019, 15, 1902238. [CrossRef]

16. Garg, S.; Garg, A.; Sahu, N.K.; Yadav, A.K. Synthesis and characterization of nanodiamond-anticancer drug conjugates for tumor targeting. Diam. Relat. Mater. 2019, 94, 172-185. [CrossRef]

17. Terada, D.; Genjo, T.; Segawa, T.F.; Igarashi, R.; Shirakawa, M. Nanodiamonds for bioapplications-specific targeting strategies. Biochim. Biophys. Acta BBA Gen. Subj. 2020, 1864, 129354. [CrossRef] [PubMed]

18. Chang, Y.-R.; Lee, H.-Y.; Chen, K.; Chang, C.-C.; Tsai, D.-S.; Fu, C.-C.; Lim, T.-S.; Tzeng, Y.-K.; Fang, C.-Y.; Han, C.-C.; et al. Mass production and dynamic imaging of fluorescent nanodiamonds. Nat. Nanotechnol. 2008, 3, 284-288. [CrossRef]

19. Schrand, A.M.; Lin, J.B.; Hens, S.C.; Hussain, S.M. Temporal and mechanistic tracking of cellular uptake dynamics with novel surface fluorophore-bound nanodiamonds. Nanoscale 2011, 3, 435-445. [CrossRef]

20. Xing, Y.; Dai, L. Nanodiamonds for nanomedicine. Nanomedicine 2009, 4, 207-218. [CrossRef] 
21. Alkahtani, M.H.; Alghannam, F.; Jiang, L.; Almethen, A.; Rampersaud, A.A.; Brick, R.; Gomes, C.L.; Scully, M.O.; Hemmer, P.R. Fluorescent nanodiamonds: Past, present, and future. Nanophotonics 2018, 7, 1423-1453. [CrossRef]

22. Jelezko, F.; Wrachtrup, J. Single defect centres in diamond: A review. Phys. Status Solidi A 2006, 203, 3207-3225. [CrossRef]

23. Wilson, E.R.; Parker, L.M.; Orth, A.; Nunn, N.; Torelli, M.; Shenderova, O.; Gibson, B.C.; Reineck, P. The effect of particle size on nanodiamond fluorescence and colloidal properties in biological media. Nanotechnology 2019, 30, 385704. [CrossRef]

24. Shershulin, V.A.; Sedov, V.S.; Ermakova, A.; Jantzen, U.; Rogers, L.; Huhlina, A.A.; Teverovskaya, E.G.; Ralchenko, V.G.; Jelezko, F.; Vlasov, I.I. Size-dependent luminescence of color centers in composite nanodiamonds. Phys. Status Solidi A 2015, 212, $2600-2605$. [CrossRef]

25. Fedyanin, D.Y.; Agio, M. Ultrabright single-photon source on diamond with electrical pumping at room and high temperatures. New J. Phys. 2016, 18, 073012. [CrossRef]

26. Su, Z.; Ren, Z.; Bao, Y.; Lao, X.; Zhang, J.; Zhang, J.; Zhu, D.; Lu, Y.; Hao, Y.; Xu, S. Luminescence landscapes of nitrogen-vacancy centers in diamond: Quasi-localized vibrational resonances and selective coupling. J. Mater. Chem. C 2019, 7, 8086-8091. [CrossRef]

27. Vervald, A.; Burikov, S.; Borisova, N.; Vlasov, I.; Laptinskiy, K.; Laptinskaya, T.; Shenderova, O.; Dolenko, T. Fluorescence properties of nanodiamonds with NV centers in water suspensions: Fluorescence properties of ND-NV in water. Phys. Status Solidi A 2016, 213, 2601-2607. [CrossRef]

28. Aslam, N.; Waldherr, G.; Neumann, P.; Jelezko, F.; Wrachtrup, J. Photo induced ionization dynamics of the nitrogen vacancy defect in diamond investigated by single shot charge state detection. New J. Phys. 2013, 15, 013064. [CrossRef]

29. Beha, K.; Batalov, A.; Manson, N.B.; Bratschitsch, R.; Leitenstorfer, A. Optimum Photoluminescence Excitation and Recharging Cycle of Single Nitrogen-Vacancy Centers in Ultrapure Diamond. Phys. Rev. Lett. 2012, 109, 097404. [CrossRef]

30. Waldherr, G.; Beck, J.; Steiner, M.; Neumann, P.; Gali, A.; Frauenheim, T.; Jelezko, F.; Wrachtrup, J. Dark States of Single Nitrogen-Vacancy Centers in Diamond Unraveled by Single Shot NMR. Phys. Rev. Lett. 2011, 106, 157601. [CrossRef] [PubMed]

31. Petrini, G.; Moreva, E.; Bernardi, E.; Traina, P.; Tomagra, G.; Carabelli, V.; Degiovanni, I.P.; Genovese, M. Is a Quantum Biosensing Revolution Approaching? Perspectives in NV-Assisted Current and Thermal Biosensing in Living Cells. Adv. Quantum Technol. 2020, 3, 2000066. [CrossRef]

32. Claveau, S.; Bertrand, J.-R.; Treussart, F. Fluorescent Nanodiamond Applications for Cellular Process Sensing and Cell Tracking. Micromachines 2018, 9, 247. [CrossRef] [PubMed]

33. Pandey, P.C.; Shukla, S.; Pandey, G.; Narayan, R.J. Nanostructured diamond for biomedical applications. Nanotechnology 2021, 32, 132001. [CrossRef] [PubMed]

34. Chrétien, D.; Bénit, P.; Ha, H.-H.; Keipert, S.; El-Khoury, R.; Chang, Y.-T.; Jastroch, M.; Jacobs, H.T.; Rustin, P.; Rak, M. Mitochondria are physiologically maintained at close to $50^{\circ} \mathrm{C}$. PLoS Biol. 2018, 16, e2003992. [CrossRef] [PubMed]

35. Bai, T.; Gu, N. Micro/Nanoscale Thermometry for Cellular Thermal Sensing. Small 2016, 12, 4590-4610. [CrossRef]

36. Karnebogen, M.; Singer, D.; Kallerhoff, M.; Ringert, R.-H. Microcalorimetric investigations on isolated tumorous and nontumorous tissue samples. Thermochim. Acta 1993, 229, 147-155. [CrossRef]

37. Suzuki, M.; Tseeb, V.; Oyama, K.; Ishiwata, S. Microscopic Detection of Thermogenesis in a Single HeLa Cell. Biophys. J. 2007, 92, L46-L48. [CrossRef]

38. Vetrone, F.; Naccache, R.; Zamarrón, A.; Juarranz de la Fuente, A.; Sanz-Rodríguez, F.; Martinez Maestro, L.; Martín Rodriguez, E.; Jaque, D.; García Solé, J.; Capobianco, J.A. Temperature Sensing Using Fluorescent Nanothermometers. ACS Nano 2010, 4, 3254-3258. [CrossRef]

39. Drabik, J.; Cichy, B.; Marciniak, L. New Type of Nanocrystalline Luminescent Thermometers Based on $\mathrm{Ti}^{3+} / \mathrm{Ti}^{4+}$ and Ti ${ }^{4+} / \mathrm{Ln}^{3+}$ $\left(\mathrm{Ln}^{3+}=\mathrm{Nd}^{3+}, \mathrm{Eu}^{3+}, \mathrm{Dy}^{3+}\right)$ Luminescence Intensity Ratio. J. Phys. Chem. C 2018, 122, 14928-14936. [CrossRef]

40. Elzbieciak-Piecka, K.; Matuszewska, C.; Marciniak, L. Step by step designing of sensitive luminescent nanothermometers based on Cr3+,Nd3+ co-doped La3-xLuxAl5-yGayO12 nanocrystals. New J. Chem. 2019, 43, 12614-12622. [CrossRef]

41. Lupton, J.M. A molecular thermometer based on long-lived emission from platinum octaethyl porphyrin. Appl. Phys. Lett. 2002, 81, 2478-2480. [CrossRef]

42. Wu, Y.; Liu, J.; Ma, J.; Liu, Y.; Wang, Y.; Wu, D. Ratiometric Nanothermometer Based on Rhodamine Dye-Incorporated F127Melamine-Formaldehyde Polymer Nanoparticle: Preparation, Characterization, Wide-Range Temperature Sensing, and Precise Intracellular Thermometry. ACS Appl. Mater. Interfaces 2016, 8, 14396-14405. [CrossRef]

43. Kucsko, G.; Maurer, P.C.; Yao, N.Y.; Kubo, M.; Noh, H.J.; Lo, P.K.; Park, H.; Lukin, M.D. Nanometre-scale thermometry in a living cell. Nature 2013, 500, 54-58. [CrossRef] [PubMed]

44. Plakhotnik, T.; Doherty, M.W.; Cole, J.H.; Chapman, R.; Manson, N.B. All-Optical Thermometry and Thermal Properties of the Optically Detected Spin Resonances of the NV-Center in Nanodiamond. Nano Lett. 2014, 14, 4989-4996. [CrossRef] [PubMed]

45. Tsai, P.-C.; Epperla, C.P.; Huang, J.-S.; Chen, O.Y.; Wu, C.-C.; Chang, H.-C. Measuring Nanoscale Thermostability of Cell Membranes with Single Gold-Diamond Nanohybrids. Angew. Chem. Int. Ed. 2017, 56, 3025-3030. [CrossRef] [PubMed]

46. Montes-Frausto, J.B.; Juarez-Moreno, K.; Can-Uc, B.; Hirata-Flores, G.A. Synthesis and cytotoxic effects of SrAl2O4 persistent luminescence nanoparticles co-doped with Eu2+/Dy3+ ions. Opt. Mater. Express 2016, 6, 1488-1499. [CrossRef] 
47. Acosta-Elías, M.; Sarabia-Sainz, A.; Pedroso-Santana, S.; Silva-Campa, E.; Santacruz-Gomez, K.; Angulo-Molina, A.; Castaneda, B.; Soto-Puebla, D.; Barboza-Flores, M.; Melendrez, R.; et al. Carboxylated nanodiamond and re-oxygenation process of gamma irradiated red blood cells: Re-oxygenation process of gamma irradiated red blood cells. Phys. Status Solidi A 2015, 212, 2437-2444. [CrossRef]

48. Hsiao, W.W.-W.; Hui, Y.Y.; Tsai, P.-C.; Chang, H.-C. Fluorescent Nanodiamond: A Versatile Tool for Long-Term Cell Tracking, Super-Resolution Imaging, and Nanoscale Temperature Sensing. Acc. Chem. Res. 2016, 49, 400-407. [CrossRef]

49. Fujiwara, M.; Sun, S.; Dohms, A.; Nishimura, Y.; Suto, K.; Takezawa, Y.; Oshimi, K.; Zhao, L.; Sadzak, N.; Umehara, Y.; et al. Real-time nanodiamond thermometry probing in vivo thermogenic responses. Sci. Adv. 2020, 6, 9. [CrossRef]

50. Yang, M.; Yuan, Q.; Gao, J.; Shu, S.; Chen, F.; Sun, H.; Nishimura, K.; Wang, S.; Yi, J.; Lin, C.-T.; et al. A Diamond Temperature Sensor Based on the Energy Level Shift of Nitrogen-Vacancy Color Centers. Nanomaterials 2019, 9, 1576. [CrossRef]

51. Yue, Y.; Wang, X. Nanoscale thermal probing. Nano Rev. 2012, 3, 11586. [CrossRef]

52. Brown, S. Taking the temperature of a cell. Nat. Nanotechnol. 2013, 500, 54-58. [CrossRef]

53. Plakhotnik, T.; Aman, H.; Chang, H.-C. All-optical single-nanoparticle ratiometric thermometry with a noise floor of $0.3 \mathrm{~K} \mathrm{~Hz}$ $-1 / 2$. Nanotechnology 2015, 26, 245501.

54. Plakhotnik, T. Diamonds for quantum nano sensing. Curr. Opin. Solid State Mater. Sci. 2017, 21, 25-34. [CrossRef]

55. Fernández-Quiroz, D.; Loya-Duarte, J.; Silva-Campa, E.; Argüelles-Monal, W.; Sarabia-Sainz, A.; Lucero-Acuña, A.; del CastilloCastro, T.; San Román, J.; Lizardi-Mendoza, J.; Burgara-Estrella, A.J.; et al. Temperature stimuli-responsive nanoparticles from chitosan-graft-poly( $N$-vinylcaprolactam) as a drug delivery system. J. Appl. Polym. Sci. 2019, 136, 47831. [CrossRef]

56. Schirhagl, R.; Chang, K.; Loretz, M.; Degen, C.L. Nitrogen-Vacancy Centers in Diamond: Nanoscale Sensors for Physics and Biology. Annu. Rev. Phys. Chem. 2014, 65, 83-105. [CrossRef]

57. Gali, A.; Fyta, M.; Kaxiras, E. Ab initio supercell calculations on nitrogen-vacancy center in diamond: Electronic structure and hyperfine tensors. Phys. Rev. B 2008, 77, 155206. [CrossRef]

58. Smeltzer, B.; Childress, L.; Gali, A. ${ }^{13}$ C hyperfine interactions in the nitrogen-vacancy centre in diamond. New J. Phys. 2011, 13, 025021. [CrossRef]

59. Barson, M.S.J.; Krausz, E.; Manson, N.B.; Doherty, M.W. The fine structure of the neutral nitrogen-vacancy center in diamond. Nanophotonics 2019, 8, 1985-1991. [CrossRef]

60. Redman, D.A.; Brown, S.; Sands, R.H.; Rand, S.C. Spin dynamics and electronic states of N-V centers in diamond by EPR and four-wave-mixing spectroscopy. Phys. Rev. Lett. 1991, 67, 4. [CrossRef] [PubMed]

61. Martin, J.P.D. Fine structure of excited _E state in nitrogen-vacancy centre of diamond. J. Lumin. 1999, 81, 237-247. [CrossRef]

62. Su, L.-X.; Lou, Q.; Zang, J.-H.; Shan, C.-X.; Gao, Y.-F. Temperature-dependent fluorescence in nanodiamonds. Appl. Phys. Express 2017, 10, 025102. [CrossRef]

63. Alkauskas, A.; Buckley, B.B.; Awschalom, D.D.; Van de Walle, C.G. First-principles theory of the luminescence lineshape for the triplet transition in diamond NV centres. New J. Phys. 2014, 16, 073026. [CrossRef]

64. Davies, G. The Jahn-Teller effect and vibronic coupling at deep levels in diamond. Rep. Prog. Phys. 1981, 44, 787-830. [CrossRef]

65. Treussart, F.; Vlasov, I.I. Photoluminescence of color centers in nanodiamonds. In Nanodiamonds; Elsevier: Amsterdam, The Netherlands, 2017; pp. 155-181, ISBN 978-0-323-43029-6.

66. Rondin, L.; Dantelle, G.; Slablab, A.; Grosshans, F.; Treussart, F.; Bergonzo, P.; Perruchas, S.; Gacoin, T.; Chaigneau, M.; Chang, H.-C.; et al. Surface-induced charge state conversion of nitrogen-vacancy defects in nanodiamonds. Phys. Rev. B 2010, 82, 115449. [CrossRef]

67. Shenderova, O.; Nunn, N.; Oeckinghaus, T.; Torelli, M.; McGuire, G.; Smith, K.; Danilov, E.; Reuter, R.; Wrachtrup, J.; Shames, A.; et al. Commercial Quantities of Ultrasmall Fluorescent Nanodiamonds Containing Color Centers; Hasan, Z.U., Hemmer, P.R., Lee, H., Migdall, A.L., Eds.; International Society for Optics and Photonics: San Francisco, CA, USA, 2017; Volume 10118, pp. 1-17.

68. Robinson, M.E.; Ng, J.D.; Zhang, H.; Buchman, J.T.; Shenderova, O.A.; Haynes, C.L.; Ma, Z.; Goldsmith, R.H.; Hamers, R.J. Optically Detected Magnetic Resonance for Selective Imaging of Diamond Nanoparticles. Anal. Chem. 2018, 90, 769-776. [CrossRef]

69. Yanagi, T.; Kaminaga, K.; Kada, W.; Hanaizumi, O.; Igarashi, R. Optimization of Wide-Field ODMR Measurements Using Fluorescent Nanodiamonds to Improve Temperature Determination Accuracy. Nanomaterials 2020, 10, 2282. [CrossRef]

70. Sekiguchi, T.; Sotoma, S.; Harada, Y. Fluorescent nanodiamonds as a robust temperature sensor inside a single cell. Biophys. Physicobiology 2018, 15, 229-234. [CrossRef]

71. Basso, L.; Cazzanelli, M.; Orlandi, M.; Miotello, A. Nanodiamonds: Synthesis and Application in Sensing, Catalysis, and the Possible Connection with Some Processes Occurring in Space. Appl. Sci. 2020, 10, 4094. [CrossRef]

72. 72. Bradac, C.; Gaebel, T.; Pakes, C.I.; Say, J.M.; Zvyagin, A.V.; Rabeau, J.R. Effect of the Nanodiamond Host on a Nitrogen-Vacancy Color-Centre Emission State. Small 2013, 9, 132-139. [CrossRef] [PubMed]

73. Pavlova, N.N.; Thompson, C.B. The Emerging Hallmarks of Cancer Metabolism. Cell Metab. 2016, 23, 27-47. [CrossRef]

74. Maruyama, H.; Kimura, T.; Liu, H.; Ohtsuki, S.; Miyake, Y.; Isogai, M.; Arai, F.; Honda, A. Influenza virus replication raises the temperature of cells. Virus Res. 2018, 257, 94-101. [CrossRef] [PubMed]

75. Kratochvílová, I.; Šebera, J.; Ashcheulov, P.; Golan, M.; Ledvina, M.; Míčová, J.; Mravec, F.; Kovalenko, A.; Zverev, D.; Yavkin, B.; et al. Magnetical and Optical Properties of Nanodiamonds Can Be Tuned by Particles Surface Chemistry: Theoretical and Experimental Study. J. Phys. Chem. C 2014, 118, 25245-25252. [CrossRef] 